\title{
Methane and nitrous oxide from ground-based FTIR at Addis Ababa: observations, error analysis, and comparison with satellite data
}

Temesgen Yirdaw Berhe et al.

Correspondence to: Temesgen Yirdaw Berhe (temiephys@gmail.com)

The copyright of individual parts of the supplement might differ from the CC BY 4.0 License. 


\section{Supplemental document}

This supplemental document has been prepared to show some points raised on the amt-2019170 manuscript from most reviewers. Here, I stated all the comments suggested by the referees point by point. This document is prepared for the manuscript "amt-2019-170", which is mainly for the $\mathrm{CH} 4$ derived from the Addis Ababa FTIR site. The following points have been discussed so that to address the questions which are not necessary to write on the manuscript.

1. To reveal the reason why we didn't use the micro-windows recommended by IRWG/NDACC in the manuscript rather other micro-windows are implemented. We discussed the points in this supplement document.

2. To reveal about the spatial criteria used in the manuscript that is $\pm 2^{0}$ for latitude and $\pm 10^{0}$ for longitude.

3. Details on the retrieval strategy applied in this manuscript. 


\section{Manuscript microwindows}
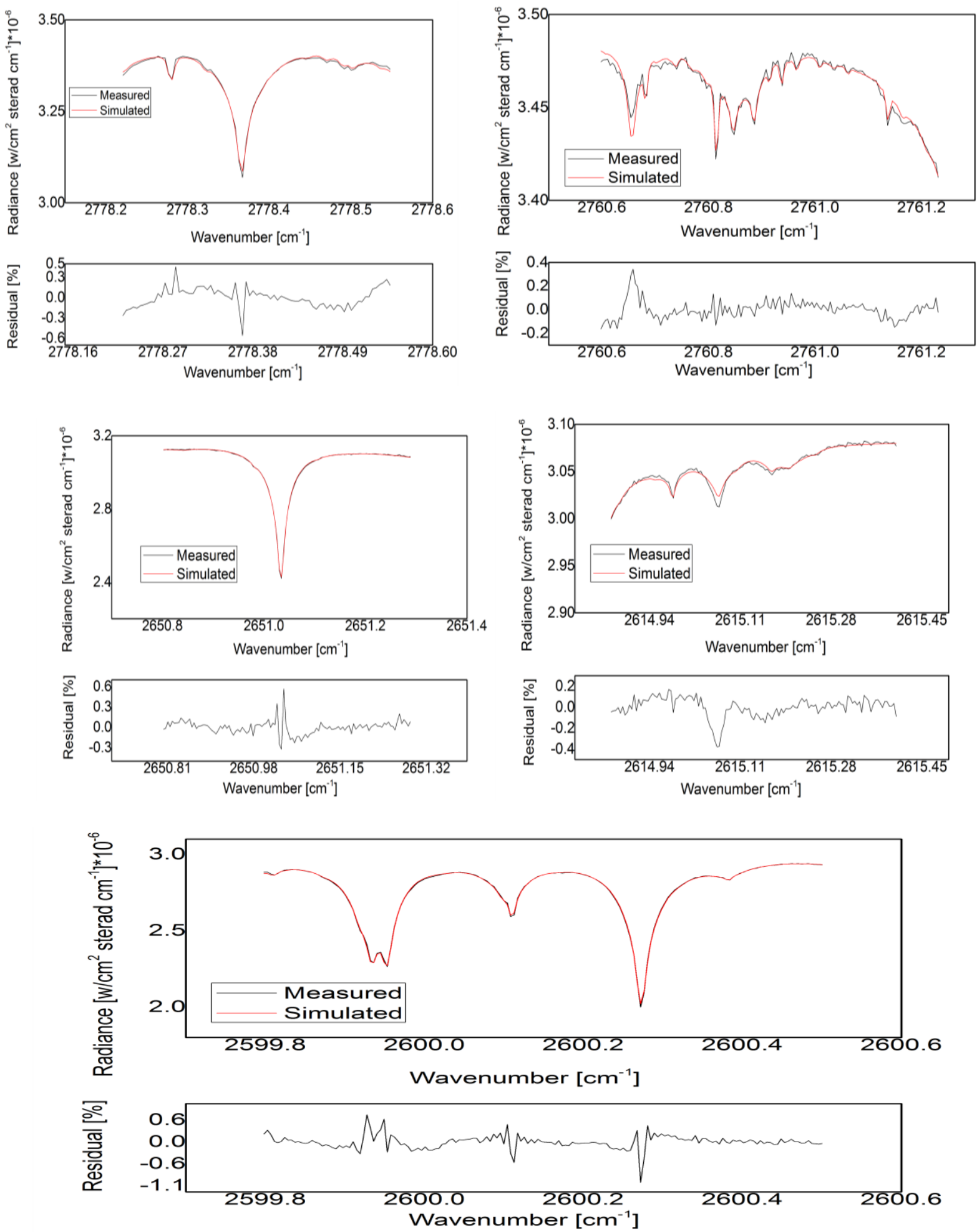

Figure 1: Measured and simulated spectrum for all the five spectral windows measured with the 125HR in Addis Ababa on the 26 Feb. 2013 at 10:17 UTC, corresponding to retrieve methane. The top two panels show the observed (red line) and simulated (black line) spectra. The bottom of the respective micro windows figure shows the residuals of the fits in all the five spectral windows. 


\section{NDACC microwindows}
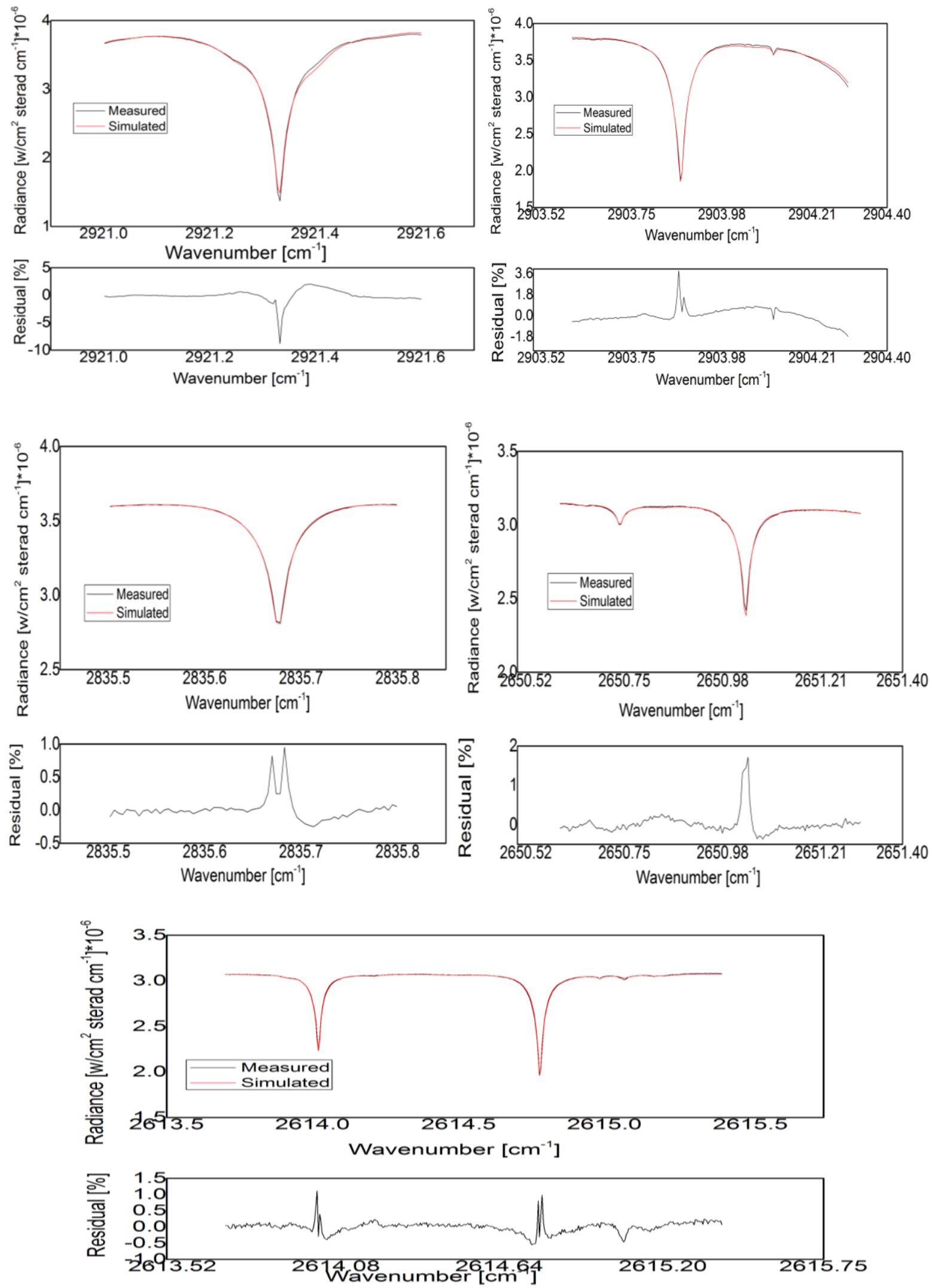

Figure 2: Measured and simulated spectrum for all the five spectral windows measured with the 125HR in Addis Ababa on the 26 Feb. 2013 at 10:17 UTC, corresponding to retrieve methane. The top two panels show the observed (red line) and simulated (black line) spectra. The bottom of the respective micro windows figure shows the residuals of the fits in all the five spectral windows. 
The above two figures 1 and 2 shows the measured and simulated spectrum fit derived using two different microwindows group. Fig 1 is for the microwindows used in the manuscript and fig 2 for the microwindows recommended by NDACC. Moreover, the figures were used to indicate that the reason why we employed the new micro windows in the manuscript.

The residuals derived from the spectrum measured on Feb 26, 2013 for both the five micro windows in the manuscript and the microwindows recommended by the IRWG/NDACC are shown Fig. 1 and Fig. 2 and summarized in Table 1. Numbers for the root-mean-square of the residuals shown in the table below for the packages of micro-windows indicate that the RMS for NDACC micro-windows are larger than that of micro-windows used in the manuscript. Thus, the microwindows implemented in the manuscript attained less RMS residuals than the recommended by NDACC.

Table 1: The difference between the five microwindows recommended by IRWG/NDACC and the microwindows used in the manuscript

\begin{tabular}{|l|l|l|l|l|l|}
\hline Gas & MW & sources & Residual(\%) & $\begin{array}{l}\text { RMS of } \\
\text { residual [\%] }\end{array}$ & \multirow{2}{*}{ DOFs } \\
\hline \multirow{4}{*}{ CH4 } & $2599.80,2600.50$ & Arndt et al., (2004) & -0.7 to 0.3 & 0.178 & \multirow{2}{*}{2.44} \\
\cline { 2 - 5 } & $2614.87,2615.40$ & IRWG/NDACC & -0.1 to 0.1 & 0.094 & \\
\cline { 2 - 5 } & $2650.80,2651.29$ & IRWG/NDACC & -0.4 to 0.3 & 0.103 & \\
\cline { 2 - 5 } & $2760.60,2761.23$ & Arndt et al., (2004) & -0.1 to 0.2 & 0.078 & \\
\cline { 2 - 5 } & $2778.22,2778.55$ & Arndt et al., (2004) & -0.3 to 0.5 & 0.145 & \\
\hline \multirow{4}{*}{ CH4 } & $2611.60,2613.35$ & IRWG/NDACC & -0.5 to 1.1 & 0.172 & \multirow{2}{*}{2.17} \\
\cline { 2 - 5 } & $2613.70,2615.40$ & IRWG/NDACC & -0.37 to 1.7 & 0.267 & \\
\cline { 2 - 5 } & $2835.55,2835.80$ & IRWG/NDACC & -0.25 to 0.96 & 0.183 & \\
\cline { 2 - 5 } & $2903.82,2903.925$ & IRWG/NDACC & -1.8 to 3.8 & 0.639 & \\
\cline { 2 - 5 } & $2914.70,2915.15$ & IRWG/NDACC & -8.85 to 1.97 & 1.157 & \\
\hline
\end{tabular}

The residual column in table 1 indicates that the residuals (\%) for the microwindows of IRWG/NDACC are high as compared to the Microwindows considered in our manuscript. Furthermore, the RMS are also confirmed that the RMS obtained from the manuscript microwindows are less than the those obtained from the recommended by NDACC. Therefore, the above results are the reasons why we selected microwindows different from those recommended by NDACC in the manuscript. 


\section{Sensitivity and other information of the manuscript micro-windows and recommended by NDACC}

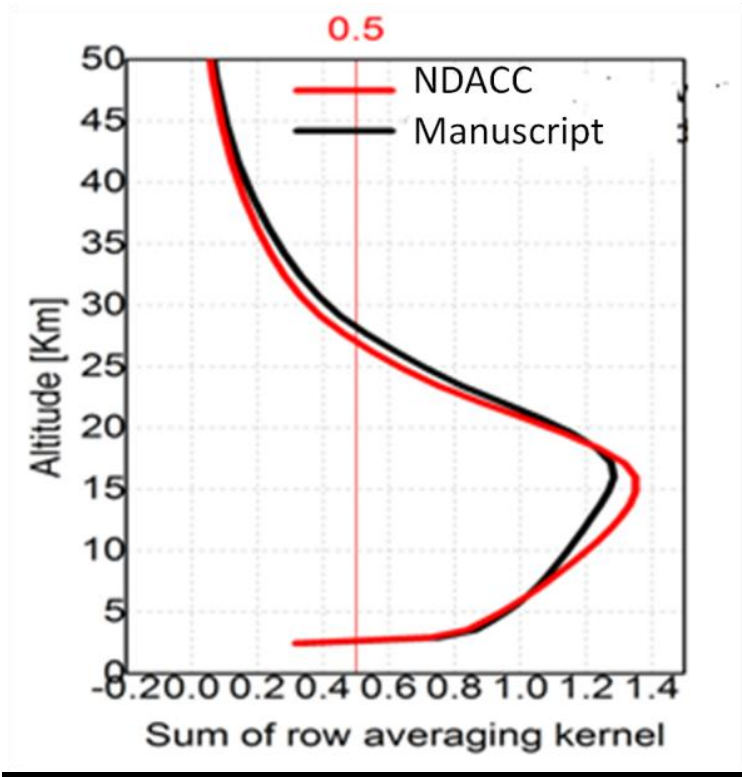

Figure 3: Sensitivity analysis of the retrieved profiles of $\mathrm{CH} 4$ at Addis Ababa using the sum of rows averaging kernels as a function of altitude for micro-windows used in the manuscript (black solid line) and those recommended by NDACC (red solid line).

The DOFs for the micro-windows used in the manuscript and recommended by NDACC are 2.44 and 2.17 respectively, for the spectrum measured on 26/2/2013 at Addis Ababa. Here the DOFs for the micro-windows used in the manuscript are somehow higher than the recommended micro-windows by NDACC. Similarly, the sensitivity of the instrument that is determined using the sum of row averaging kernel has also different. Moreover, an upper altitude value of our micro-windows extends to around $27.0 \mathrm{~km}$ and that of the NDACC is at around $26 \mathrm{~km}$ (see Figure 3). 

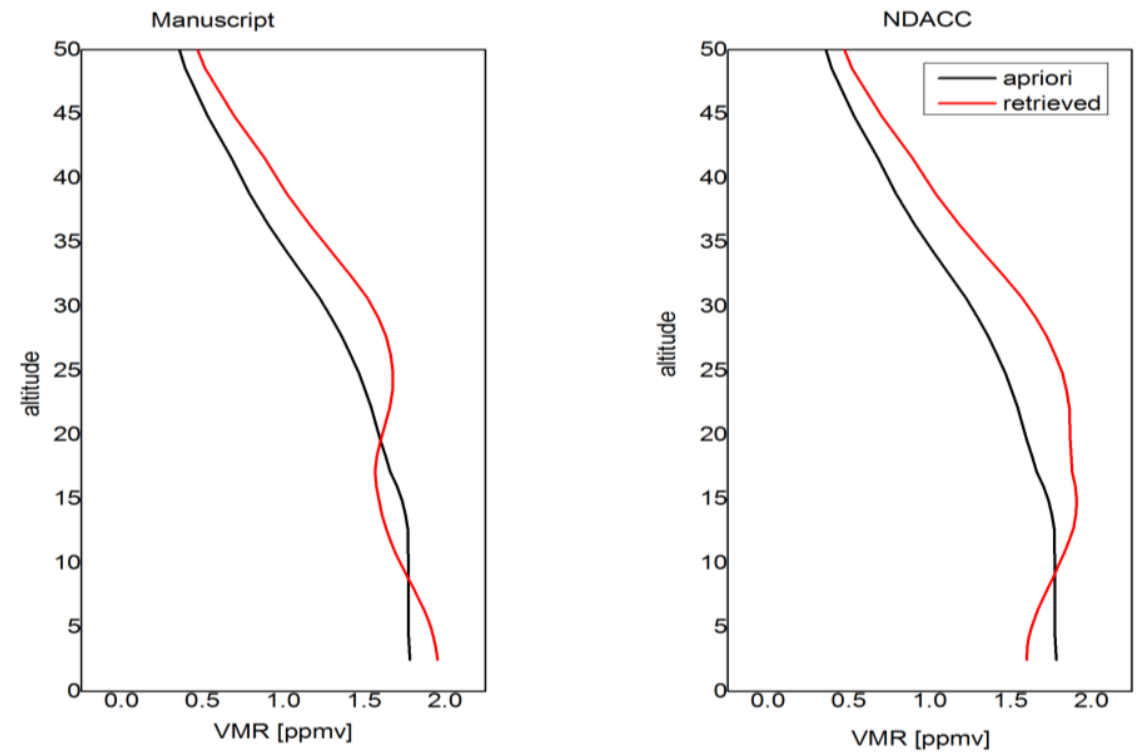

Figure 4: The retrieved and a priori profiles of $\mathrm{CH} 4$ at Addis Ababa derived using the Microwindows used in the manuscript(left) and the recommended by NDACC (right).

Figure 4.shows the retrieval results of FTIR CH4 and the a priori produced from WACCM using a package of microwindows applied in the manuscript and those recommended by NDACC. A large difference is shown in the upper troposphere and lower stratosphere of Addis Ababa site in the cases of NDACC microwindows as compared to those derived from the manuscript microwindows. Thus, the difference indicates a large error has been shown in the right panel of figure 4 , which also shown in error budget figure 5 .
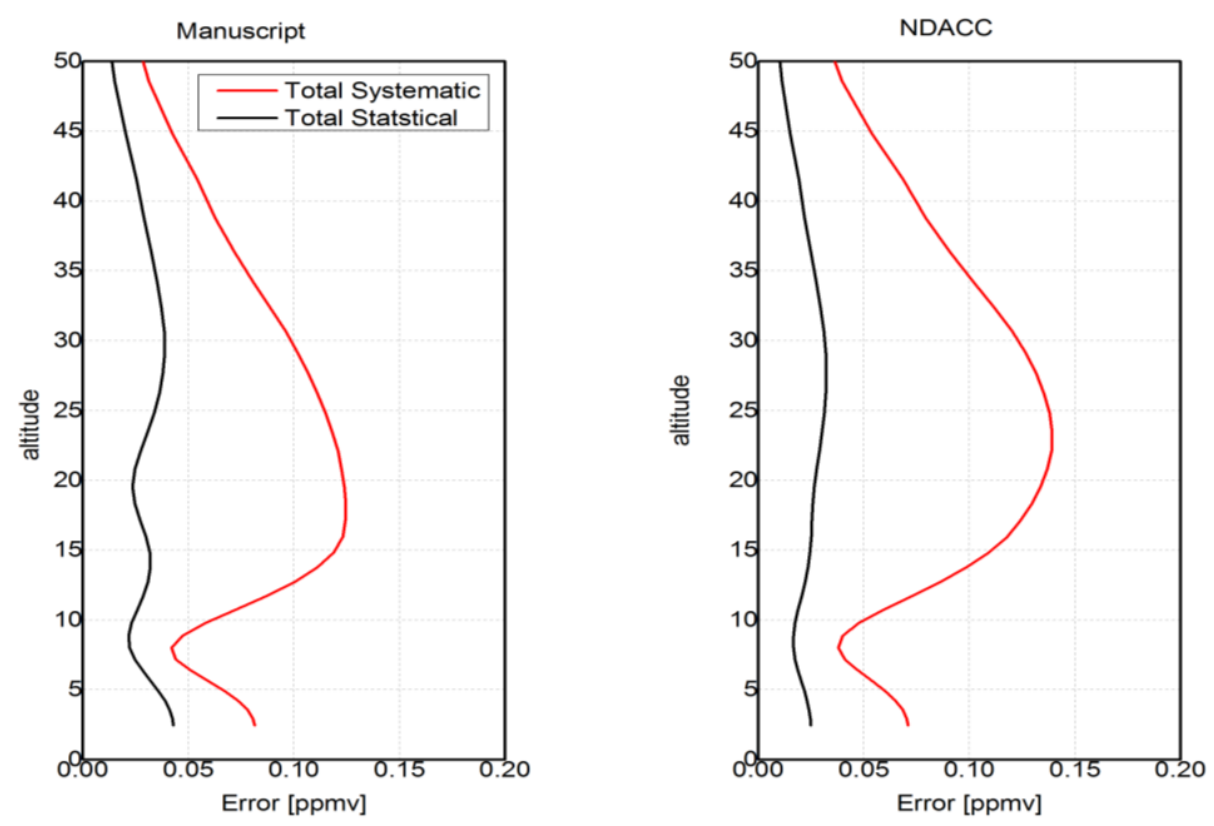

Figure 5: The total statistical and systematic error contribution on the retrieval of $\mathrm{CH} 4$ at Addis Ababa for the micro-windows used in the manuscript (left) and recommended by NDACC (right).

In figure 5, the total systematic error contribution during the retrieval of methane from FTIR using the recommended micro-windows by NDACC shows larger than the manuscript micro windows mainly in the upper tropospher and lower stratosphere. Therefore, the selection of the microwindows in our manuscript gives us a better result. 
Table 2 shows the summary of the comparison of PCL derived from the microwindows used in the manuscript and from NDACC. Although, the measured spectrum used here in this supplemental document is similar for both the microwindows, the mean square error is 1.4 that indicates the two results are somehow different.

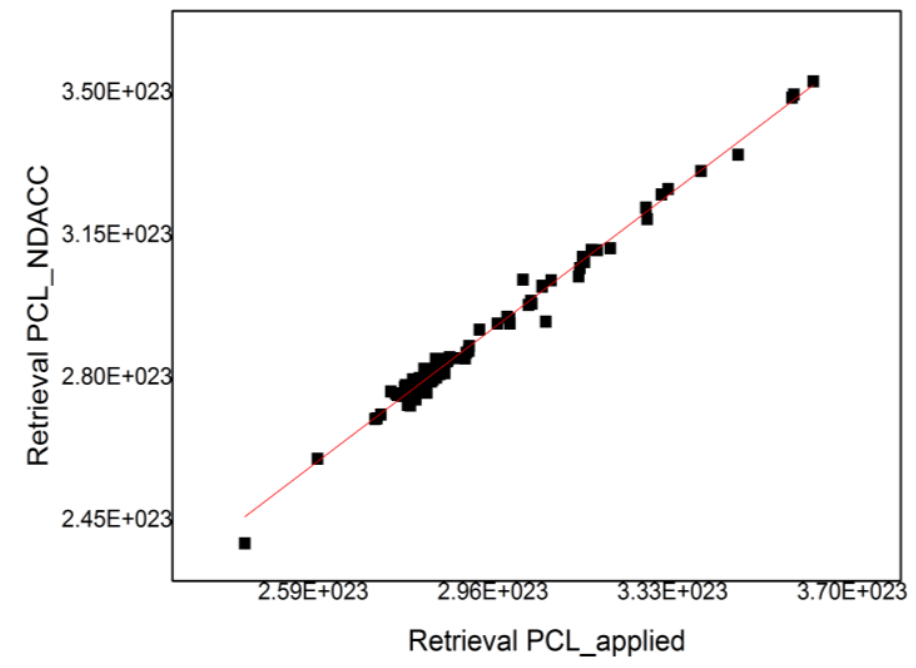

Figure 6: comparison of PCL of $\mathrm{CH} 4$ derived using the microwindows employed in the manuscript and microwindows recommended by IRWG/NDACC.

Table 2: The summary of the comparison between PCL $(2.45-27 \mathrm{~km})$ obtained by applying the microwindows selected for Addis Ababa site and the microwindows recommended by NDACC.

\begin{tabular}{|l|l|l|l|l|l|}
\hline $\begin{array}{l}\text { Pairs of } \\
\text { compared }\end{array}$ & $\begin{array}{l}\text { Number } \\
\text { of } \\
\text { comparisons }\end{array}$ & $\begin{array}{l}\text { Mean square } \\
\text { error (\%) }\end{array}$ & $\begin{array}{l}\text { Mean error } \\
(\%)\end{array}$ & $\begin{array}{l}\text { SD from Mean } \\
\text { error (\%) }\end{array}$ & $\begin{array}{l}\text { Correlation } \\
\text { coefficient }\end{array}$ \\
\hline $\begin{array}{l}\text { MW used Vs } \\
\text { Recommended } \\
\text { by NDACC }\end{array}$ & 163 & 1.4 & 1.1 & 0.76 & 0.98 \\
\hline
\end{tabular}

\section{Summary}

This supplemental document was prepared to clarify the reason why we use the microwindows which are different from microwindows recommended by NDACC.

Here, the residuals, DOFs, the profile derived, sensitivity and error budget during the retrieval of $\mathrm{CH}_{4}$ from FTIR at Addis Ababa site by employing the microwindows used in the manuscript and those recommended by NDACC are discussed. All the above results lead us to conclude that the micro windows applied in the manuscript has better results as compare to the microwindows recommended by NDACC. 


\section{latitudinal and longitudinal variability}
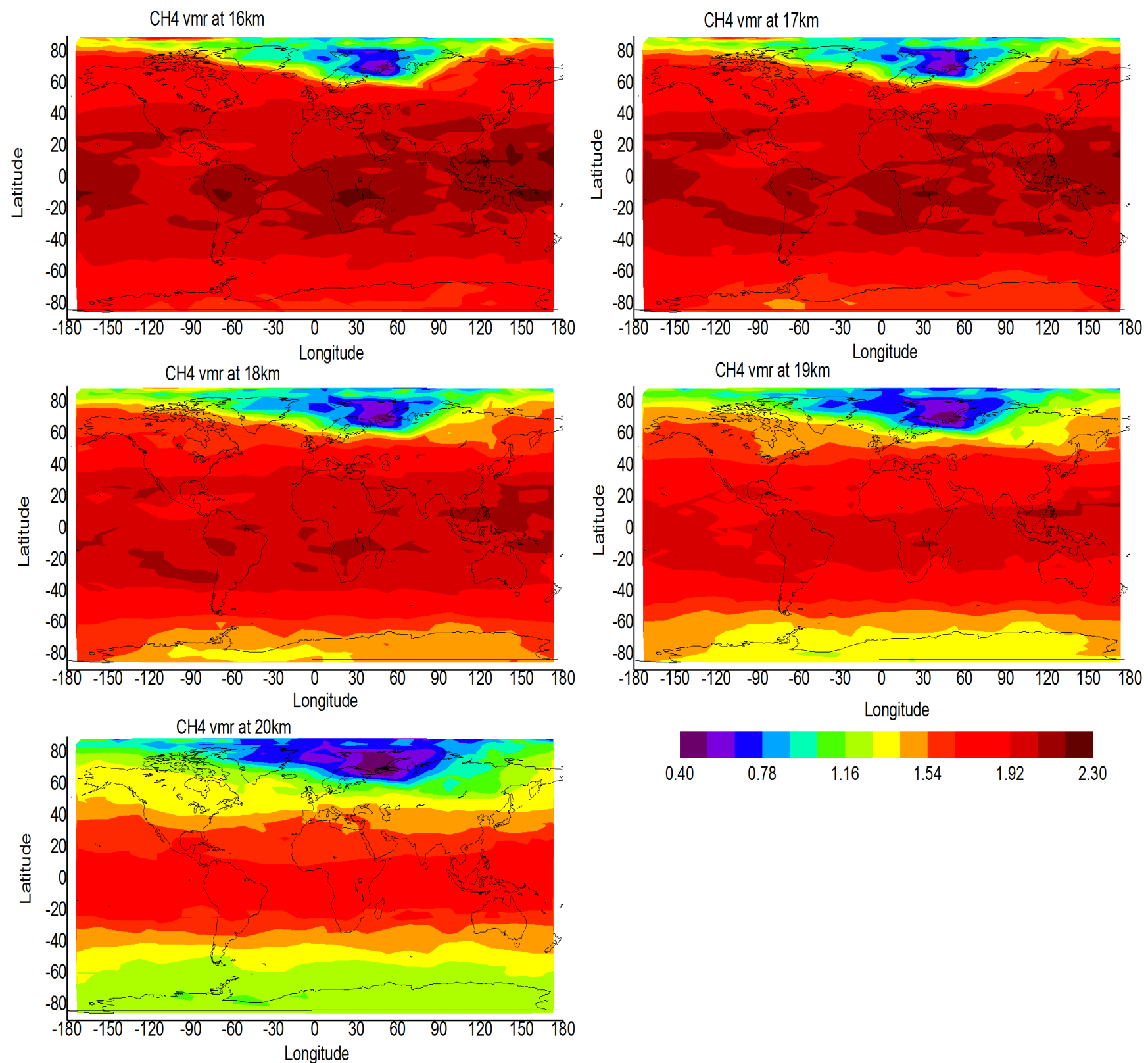

Figure 7: global Methane profile measured by MIPAS at Feberoury 2010 for five layers (16, $17,18,19$ and $20 \mathrm{~km})$.

Figure 7 shows the variation of the profile has more pronounced in the latitudinal than the longitudinal as a result the spatial criteria that we consider in the manuscript are narrow for latitude and wide range for longitude. This helps to address the question on the spatial criteria used in the manuscript. 


\section{Retrieval set up}

In this paper, we have used a Tikhonov regularization method on a logarithmic scale to retrieve the vertical profiles, from the result of iterative solution given by

$$
X_{i+1}=X_{i}+\left(K_{i}^{T} S_{\epsilon}^{-1} K_{i}+R\right)^{-1}\left[K_{i}^{T} S_{\epsilon}^{-1}\left(Y-F\left(X_{i}\right)\right)-R\left(X_{i}-X_{a}\right)\right]
$$

Determination of the appropriate weight of the constraint is a critical part of the design of any retrieval strategy. In case of Tikhonov regularization the matrix becomes $\mathrm{R}=\alpha \mathrm{L}^{\mathrm{T}} \mathrm{L}$, where $\alpha$ is a regularization parameter and $\mathrm{L}$ is a regularization matrix and the iterative solution

$$
X_{i+1}=X_{i}+\left(K_{i}^{T} S_{\epsilon}^{-1} K_{i}+\alpha L^{T} L\right)^{-1}\left[K_{i}^{T} S_{\epsilon}^{-1}\left(Y-F\left(X_{i}\right)\right)-\alpha L^{T} L\left(X_{i}-X_{a}\right)\right]
$$

The parameter $\alpha$ determines the weight of the regularization and it is also important to choose $\alpha$ appropriate to the problem. One way to fix this parameter is the L-curve method [1].

There are several possibilities to set up regularization matrix L, the simplest one being the identity matrix, $\mathrm{I}=\mathrm{L}$. This results in a retrieval equivalent to the optimal estimation with a diagonal a priori covariance matrix $S_{a}=I / \alpha$. In order to obtain a smooth solution the discrete first derivative operator is useful as a smoothing matrix $\mathrm{L}=\mathrm{L}_{1}$

In the case that two different types of state parameters being jointly fitted, which require different approaches of regularization, it is necessary to have a formalism which supports both types of constraints. In order to gain understanding of the smoothing effect of the offdiagonal elements of $S_{a}$, to express $L_{1}{ }^{T} L_{1}$ by a matrix of the format of an inverse covariance matrix as

$$
S_{a}^{-1}=\alpha L_{1}^{T} L_{1}
$$

This means that an a priori covariance matrix can be set up that acts approximately in the same way as the discrete first derivative operator $L_{1}$. This equivalence is only approximate since truncation of the expansion causes a regular matrix $S_{a}^{-1}$ being transformed to a singular matrix of the formL ${ }_{1}{ }^{\mathrm{T}} \mathrm{L}_{1}$. Therefore, optimal estimation formalism can be used either in the original sense of weighting the measured and the a priori profile or in the sense of smoothing the solution without considerably shifting it towards the a priori profile. Because of the approximate equivalence of $\mathrm{OE}$ and $\mathrm{TP}$ regularization methods, we henceforth use the optimal estimation terminology.

The retrieval is performed on a fine vertical grid from 2.45 to $85 \mathrm{~km}$ and is stabilized by a first order Tikhonov constraint, $\mathrm{R}=\alpha \mathrm{L}_{1}{ }^{\mathrm{T}} \mathrm{L}_{1}$ where $\alpha$ is the strength of the constraint and $\mathrm{L}_{1}$ is the first order derivative [2], which smoothest the solution without biasing it towards the a priori profile.

The regularization strength $\alpha$, is determined by finding a trade-off between the number of degrees of freedom (a measure of the amount of information in methane and nitrous oxide retrieval), which is given by the trace of the averaging kernel and the noise induced error (Rodgers, 2000). Regularization strength $\alpha$, of $2.5 \times 10^{4}$ was found optimum for $\mathrm{CH} 4$ retrieval. 


\section{Reference}

[1] Hansen, C.: Analysis of discrete ill-posed problems by means of the L-curve, Soc. Indust. Appl. Math., 34, 561-580, 1992.

[2] Tilman Steck.(2002). Methods for determining regularization for atmospheric retrieval problems. Applied Optics Vol. 41, No. 9. 